\title{
Do US Government Tax Revenues and Expenditures Respond to Debt Levels and Economic Conditions Asymmetrically over the Business Cycle?
}

\author{
Steven P Cassou ${ }^{1} \&$ Hedieh Shadmani ${ }^{2}$ \\ ${ }^{1}$ Department of Economics, Kansas State University, Manhattan, KS, USA \\ ${ }^{2}$ Department of Economics, Fairfield University, Fairfield, CT, USA \\ Correspondence: Hedieh Shadmani, Department of Economics, Fairfield University, 1073 N Benson Road, Fairfield, \\ CT 06824, USA.
}

Received: February 9, 2018

Accepted: February 27, 2018 Available online: March 11, 2018

doi:10.11114/aef.v5i3.3004

URL: https://doi.org/10.11114/aef.v5i3.3004

\begin{abstract}
This paper empirically investigates whether there are asymmetries in the responses of US government tax revenue and expenditure to debt levels and economic conditions over the business cycle. State of the art regime switching regression models, including Threshold Regression and Markov Switching, are investigated. Both sides of the government budget show asymmetries, but the asymmetries for tax revenue show greater statistical significance. The results show that both tax revenue and expenditure respond to high debt levels, with the asymmetry in this response showing that fiscal authorities take weaker action in response to debt during poor economic times. In addition, the asymmetric response to economic conditions for both sides of the budget shows that stronger countercyclical policy is taken during poor economic times.
\end{abstract}

Keywords: asymmetric fiscal policy, fiscal policy sustainability, cyclicality, government expenditure, tax revenue

\section{Introducation}

Policy makers consider many things in formulating fiscal policy and priorities likely shift in response to economic conditions. Among these priorities are whether to engage in economic stimulation or to respond to the level of debt. Both of these priorities have seen considerable academic interest and developments in time series econometric methods has aided these inquiries. This paper contributes to this literature by using state of the art regime switching models, including Threshold Regression and Markov Switching models, to address these questions. Here we investigate the extent to which United States (US) policy makers adjust their decisions about tax revenue and spending in response to debt levels or undertake countercyclical policy during strong and weak economic times.

The idea that policy makers implement asymmetrical policy in which they undertake stronger countercyclical actions during economic downturns than during economic upturns has long been held as an anecdotal truth. But finding empirical support has required development of new econometric methods. Investigation of monetary policy has a bit of a head start in this regard, with the development of explicit optimization models by Ruge-Murcia $(2003,2004)$ and Surico (2007) along with empirical confirmation of these models by Ruge-Murcia (2003, 2004) as well as Cassou, Scott and Vázquez (2012) and Cassou, Shadmani and Vázquez (2013). So far, formal optimization models for fiscal policy are still elusive, but there is mounting empirical evidence that fiscal policy is asymmetric as results by Quintos (1995), Golinelli and Momigliano (2008), Balassone, Francese and Zotteri (2010), Sorensen and Yosha (2001), and Cassou et al. (2017) have found. ${ }^{1}$ This paper contributes to this literature by using Threshold Regression and Markov Switching models to investigate this issue. Furthermore, it differs from previous work which often focused on the primary surplus (deficit) to investigate the revenue and spending side of the government balance sheet individually.

Recently a distinct but related body of work has investigated whether the effect of fiscal policy shocks vary over the business cycle. For example, Auerbach and Gorodnichenko (2012) focus on the size of spending multipliers in

\footnotetext{
${ }^{1}$ It is useful to note that both implementation and legislative lags for fiscal policy are considerably longer than for moneraty policy. Hence, we expect a larger degree of persistance in government spending and tax revenues.
} 
recessions and expansions. Using smooth transition vector autoregression (STVAR) regime switching models, they find that fiscal policy is considerably more effective in recessions than in expansions. A more recent paper by Ramey and Zubairy (2017) investigates whether the size of the US government spending multipliers depend on the amount of slack, as measured by the unemployment rate, or on whether interest rates are near the zero lower bound. They construct a quarterly historical data set for the US, including episodes of large variations in government spending, wide fluctuations in unemployment, and long periods of near the zero lower bound interest rates. Using different methodologies and specifications, surprisingly, they find no evidence of substantial asymmetry in government spending multipliers over different states of the economy. Our paper is different from this strand of literature as it focuses on the asymmetry in the reaction of the fiscal variables during recessions and expansions rather than an asymmetry in the effect of fiscal policy.

This paper also contributes to the literature on the sustainability of debt. This is a somewhat longer literature, with interest dating at least back to the mid 1980s. ${ }^{2}$ This literature has several approaches. One approach uses unit root methods and often finds unsustainable debt levels. ${ }^{3}$ Another approach, advocated by Bohn $(1998,2007)$, uses a policy reaction methodology. His work, as well as related work by Collignon (2012) and Cassou et al. (2017), have found that debt policy in the US is sustainable. ${ }^{4}$ By estimating policy reaction equations for the two sides of the US government balance sheet, we also contribute to the sustainability debate.

We find several important results regarding the policy reactions for both budget components in the United States. First, both sides of the budget show that there is a high degree of policy persistence, that policy responds to higher debt and to business cycle conditions. However, the statistical significance of these responses is only strong for policy persistence. The response to economic conditions is statistically significant in most models while the response to debt levels is statistically significant in only a few models. The weak statistical evidence for the connection between policy and debt is important in and of itself as it does not show that policy is consistent with debt sustainability. In addition, both tax revenue and government spending exhibit asymmetric behavior, but only in the tax revenue endogenous threshold model do we find this to be statistically significant. However, because the linear model is not nested in the Markov Switching model, directly testing this hypothesis is not feasible. Taken as a whole, these results show that policy makers undertake asymmetric countercyclical policy, with stronger action taken when poor economic conditions prevail. Furthermore, the response to lagged debt also has a countercyclical policy interpretation. We find that during good economic times policy makers increase taxes and cut spending to a greater extent in response to rising debt than they do in poor economic times.

The rest of the paper is organized as follows. In Section 2 we describe the empirical models analyzed in this paper and in Section 3 we discuss the empirical findings. Finally, Section 4 concludes.

\section{Empirical Models}

Three related empirical models are investigated. The simplest model is a basic Linear Regression model (LM), while the others are popular nonlinear regime switching regression models including a Threshold Regression model (TR) and a Markov Switching Regression (MS). The regime switching models allow us to investigate asymmetry in the reaction of government spending and tax revenue to debt levels and economic conditions. We include the LM model as a baseline in which there is no asymmetry. This allows us to show the extent to which results are impacted when asymmetries are introduced. This extent can be formally tested with the TR model which is piecewise linear and can nest the basic linear model as a special case.

Threshold models have seen increased interest in fiscal policy analysis. These models can take different formulations. For instance, those used by Golinelli and Momigliano (2008) and Balassone, Francese and Zotteri (2010) are known as two parameter models because the threshold allows differences in only one parameter, while the formulations considered in this paper are known as two sample models and could nest the two parameter models as restricted cases. ${ }^{5}$

Following Balassone et al. (2010), we focus on the tax revenue and primary expenditure components of the fiscal budget. This means that in all three empirical formulations, the policy variable depends on its lagged value, the lagged debt, and the lagged output gap. Including the lagged dependent variable as one of the explanatory variable allows for

\footnotetext{
${ }^{2}$ See Trehan and Walsh (1988), Kremers (1989) or Hakkio and Rush (1991) for early investigations of this issue.

${ }^{3}$ See for instance, Trehan and Walsh (1988).

${ }^{4}$ According to the policy reaction interpretation provided in Bohn $(1998,2007)$, debt policy is sustainable if policy makers take corrective measures and improve their budget in response to an increase in debt to GDP ratio.

${ }^{5} \mathrm{We}$ also investigated the two parameter models and tested the restrictions implied between them and the two sample models. We always rejected the restrictions, so here we only present the more general two sample models.
} 
fiscal policy persistence and the existence of an optimal fiscal policy inertia. ${ }^{6}$ Moreover, including lagged explanatory variables allows us to interpret our models as a fiscal policy reaction function where the policy makers only respond to the variables in their information set. Furthermore, considering the implementation lag associated with fiscal policy, using lagged variables is a more appropriate way to study the fiscal reactions.

The LM can be written as:

$$
X_{t}=\alpha+\beta_{1} X_{t-1}+\beta_{2} d_{t-1}+\beta_{3} w_{t-1}+\varepsilon_{t},
$$

where $X_{t}$ is the ratio of one of the budget components (tax revenue $X_{t}^{R}$ or primary expenditure $X_{t}^{G}$ ) to GDP at date $t, d_{t-1}$ is the ratio of federal debt to GDP at date $t-1$, and $w_{t-1}$ is the output gap at date $t-1$, defined as the deviation of the observed annual output growth rate from its long-term value. ${ }^{7}$

The various anticipated signs for the parameters have been discussed in various places in the literature. For instance, following the arguments in Bohn (1998), sustainability of fiscal policy should be marked by negative values of $\beta_{2}$ when $X_{t}=X_{t}^{G}$, and positive values of $\beta_{2}$ when $X_{t}=X_{t}^{R}{ }^{8}$. Intuitively, for the primary expenditure regression, a negative value for $\beta_{2}$ indicates that as lagged debt increases, policy makers take action to reduce spending $X_{t}^{G}$, and for the tax revenue regression, a positive value for $\beta_{2}$ indicates that as lagged debt increases, policy makers take action to increase tax revenue $X_{t}^{R}$. Both of these reactions result in lower debt loads in the following period and hence are interpreted as exhibiting a sustainable policy. Also, as noted in Balassone et al. (2010), the sign of $\beta_{3}$ depends on whether policy is procyclical or countercyclical. For the primary expenditure regression, a positive value for $\beta_{3}$ corresponds to a procyclical policy, where higher values of the lagged output gap are followed by higher government spending, whereas a negative value for $\beta_{3}$ corresponds to a countercyclical policy. Conversely, for tax revenue regression a positive value for $\beta_{3}$ corresponds to a countercyclical policy, where higher values of the lagged output gap are followed by higher tax revenue, while a negative value for $\beta_{3}$ corresponds to a pro-cyclical policy.

Part of our empirical focus will be on a popular asymmetry hypothesis in which the policy variable, $X_{t}$, responds to the explanatory variables differently depending on whether the economy is strong or weak. One of the models used to investigate this asymmetry is a type of TR model. For the application here, we replace the explanatory variables in (1) with interaction terms in which a dummy indicating the strength of the economy at period $t-1, I_{t-1}$, is multiplied by each of the variables to get

$$
\begin{aligned}
& X_{t}=\alpha I_{t-1}+\beta_{1} I_{t-1} X_{t-1}+\beta_{2} I_{t-1} d_{t-1}+\beta_{3} I_{t-1} w_{t-1}+\alpha^{\prime}\left(1-I_{t-1}\right) \\
& +\beta_{1}^{\prime}\left(1-I_{t-1}\right) X_{t-1}+\beta_{2}^{\prime}\left(1-I_{t-1}\right) d_{t-1}+\beta_{3}^{\prime}\left(1-I_{t-1}\right) w_{t-1}+\varepsilon_{t},
\end{aligned}
$$

where $X_{t}=X_{t}^{R}$ or $X_{t}^{G}$, and $I_{t-1}$ is given by:

$$
I_{t-1}= \begin{cases}0 & \text { for } w_{t-1} \leq w^{T}, \\ 1 & \text { for } w_{t-1}>w^{T},\end{cases}
$$

and $w^{T}$ is referred to as the threshold value and is modeled using the lagged output gap for our study. We investigate both exogenous and endogenous threshold values in the empirical section. Here we interpret values for the indicator function equal to one as indicating the economy is in a strong part of the business cycle and values equal to zero as indicating the economy is in a weaker part of the business cycle.

The parameters of (2) can provide evidence for a number of interesting policy questions. For instance, $\beta_{2} \neq \beta_{2}$ or $\beta_{3} \neq$ $\beta_{3}$ implies asymmetry in the response of the policy variable to debt levels and economic conditions. If $\beta_{2} \neq \beta_{2}$, then there is evidence that the budget component responds to lagged debt differently when the economy is doing well than

\footnotetext{
${ }^{6}$ Afonso, Agnello and Furceri (2010) provided empirical evidence of fiscal policy persistence in a cross-country study. The existence of an optimal fiscal policy inertia is justifiable as the fiscal authority aims at reaching the optimal target for the policy variable in small steps due to economic uncertainty.

${ }^{7}$ Primary expenditure is government current expenditure net of interest payment. There are alternative, but related, formulations used in the literature. For instance, Golinelli and Momigliano (2008) focus on the cyclically-adjusted primary balance and prefer to use differenced levels as the dependent variable. Balassone et al. (2010) used the lagged value of the other budget items and the change in interest spending and its lagged level as other explanatory variables.

${ }^{8}$ To be more precise, Bohn (1998) uses the primary surplus (government tax revenue minus government spending net of interest payment) as dependent variable. For his model, sustainability is associated with a positive coefficient for the lagged debt.
} 
when it is not. Similarly, if $\beta_{3} \neq \beta_{3}$, then there is evidence that the budget component responds to the lagged output gap differently when the economy is doing well than when it is not. It is also useful to note that (1) is nested in (2). So one can test whether the TR model fits better than the basic linear regression model by performing an $F$ test on the null that $\alpha=\alpha, \beta_{1} \neq \beta_{1}^{\prime}, \beta_{2} \neq \beta_{2}^{\prime}$, and $\beta_{3} \neq \beta_{3}^{\prime}$.

Finally, the last part of our empirical investigation focusses on a two-state MS model. Here a nonlinear relationship between the policy variable and the explanatory variables is given by:

$$
X_{t}=\alpha\left(s_{t}\right)+\beta_{1}\left(s_{t}\right) X_{t-1}+\beta_{2}\left(s_{t}\right) d_{t-1}+\beta_{3}\left(s_{t}\right) w_{t-1}+\sigma\left(s_{t}\right) u_{t},
$$

where $u_{t}$ is a standard normal random variable and $S_{t}$ denotes the unobservable regime or state variable. The state variable has values of either 1 or 2 and follows a first-order two-state Markov process with transition matrix given by:

$$
P=\left(\begin{array}{cc}
p_{11} & 1-p_{22} \\
1-p_{11} & p_{22}
\end{array}\right),
$$

where the row $j$, column $i$ element of $P$ is the transition probability $P_{i j}$, which is the probability that state $i$ will be followed by state $j$. Since the transition probabilities beginning in each state sum to 1 , the off diagonal terms are given by $P_{12}=1-P_{11}$ and $P_{21}=1-P_{22}$. The MS model has two main advantages over the TR formulations. First, it allows for changes in the size of shocks over the sample of study and second, it allows for an interaction between fiscal policy asymmetries with changes in shock volatility.

\section{Empirical Results}

Our empirical analysis uses quarterly data for the US economy from the first quarter of 1955 to the fourth quarter of 2015. With the exception of a few years of the government debt, the data was obtained from the Federal Reserve Bank of St. Louis data bank. ${ }^{9}$

The various series used in the empirical models were computed from the raw data as follows. The tax revenue series was obtained by dividing 100 times the federal government current receipts (FGRECPT) by the nominal GDP series (GDP), while the primary expenditure series was obtained by dividing 100 times the federal government current expenditure (FGEXPND) minus federal government interest payments (A091RC1Q027SBEA) by the nominal GDP series. ${ }^{10}$ The debt to GDP ratio was obtained by dividing the total public debt series (GFDEBTN) by the nominal GDP series and the output gap series was computed by the difference between the observed annual growth rate and the average annual growth rate. ${ }^{11}$

Before describing the empirical results, let us comment a bit about the behavior of the different time series. Figure 1 shows plots of the variables of interest along with a plot of the primary deficit. These plots also indicate recession periods by using shaded regions. The first plot shows the primary deficit to GDP ratio which was computed by subtracting the federal government revenue series to GDP ratio described above from the federal government primary expenditure while the second plot shows the revenue and spending series individually. As one

\footnotetext{
${ }^{9}$ The Federal Reserve Bank of St. Louis only has quarterly debt data from 1966:01 to the present, so to get the additional 11 years back to 1955:01, we used data from the US treasury which can be found at http://www.treasurydirect.gov/govt/reports/pd/mspd/mspd.htm.

${ }^{10}$ Government current receipts include current tax receipts, contributions for government social insurance, income reeiots on assets, current transfer receipts, and current surplus of government enterprises. Government current expenditures include consumption expenditures, current transfer payments, interest payments, and subsidies. More detail can be found at https://www.bea.gov/national/pdf/nipaguid.pdf

${ }^{11}$ In particular, we computed the growth rate in percentage terms by multiplying 100 times the log difference between the current value of real GDP (GDPC1) and the value four quarters earlier. Next these growth rates were averaged and then the average was subtracted from the annual growth rate series to give a series that has positive values when the current growth rate exceeds the average and negative values when the growth rate is below the average.

We choose the output gap definition described above over the output gap based on the HP filter for two main reasons. First, the use of the HP output gap introduces an endogeneity issue in the estimation of our empirical fiscal reaction function since the HP filter is a two-sided filter. Second, the interpretation of the empirical fiscal equation as a fiscal reaction function become dubious when the HP output gap is a regressor since the HP output gap uses, by construction, much more information on GDP than the one available for the policy maker at the time of fiscal policy implementation.
} 

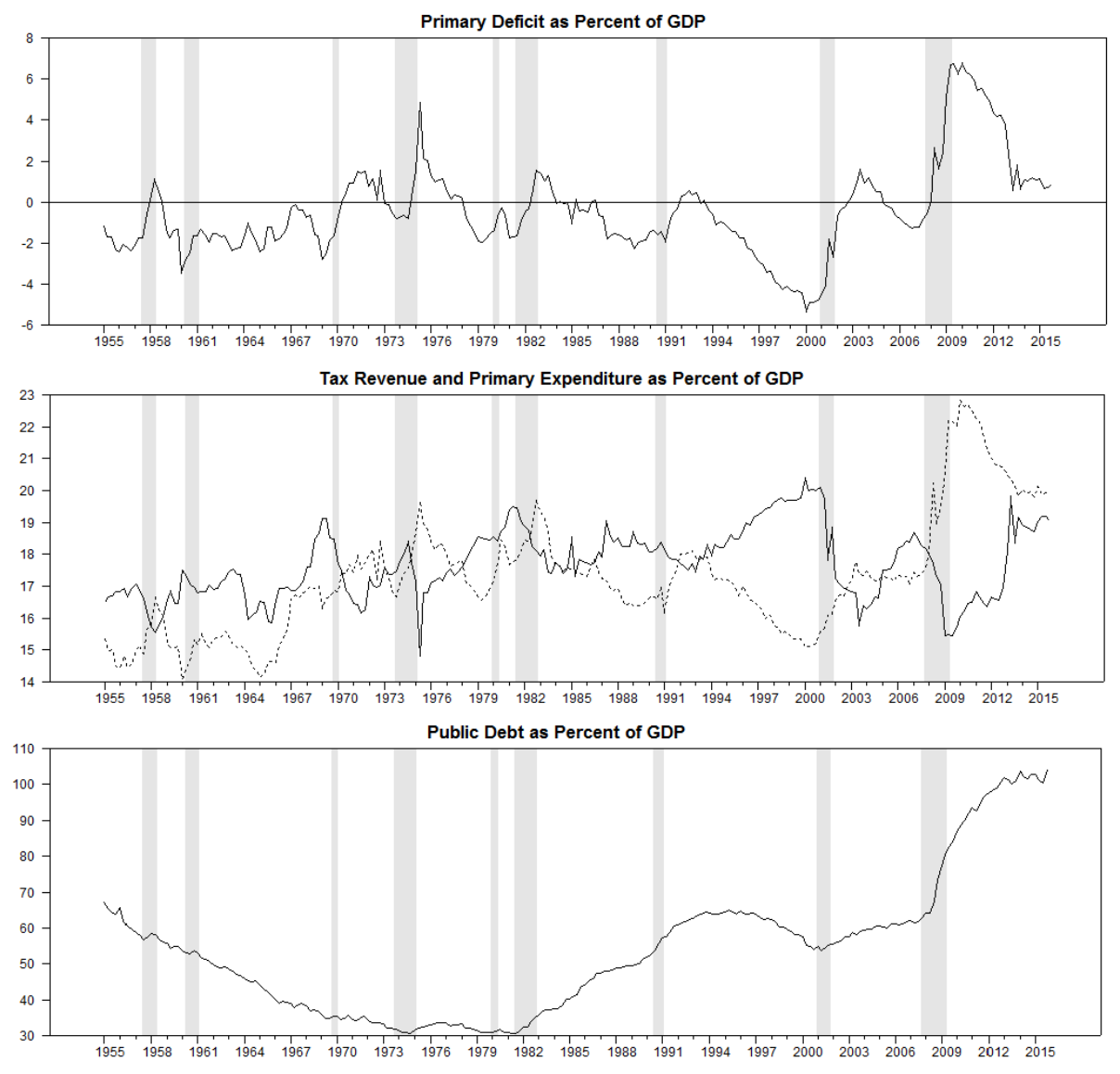

Output Gap (deviations of annual growth rate from its mean)

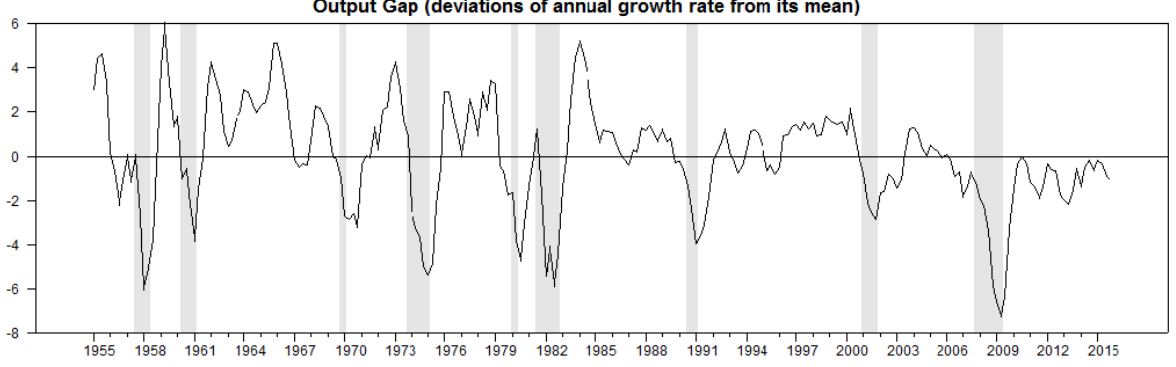

Figure 1. Primary Deficit, Tax Revenue and Primary Expenditure, Public Debt, Output Gap

would expect, the primary deficit increases during the recessionary periods reflecting countercyclical policy. This countercyclical policy can also be seen in the individual tax and spending series in the second plot where tax revenue falls and primary expenditure rises during recessions. Moreover, these series exhibit co-movements with each other. Later we exploit this co-movement by estimating a seemingly unrelated regression (SUR) model as a robustness investigation. The third plot shows the movement of the debt to GDP ratio. As one would expect, this variable tends to increase during bad economic times. In particular, during recessions, policy makers are more concerned with getting the economy back on track by spending more and cutting taxes and this results in higher deficits which leads to rising debt. The fourth plot displays the output gap. Here it can be seen that there is a sharp decrease in the output gap during the recessionary periods. For this reason, we use the output gap as the indicator for the business cycle in the TR model. 
Table 1. Federal Government Tax Revenue (1955:1 - 2015:4)

\begin{tabular}{|c|c|c|c|c|}
\hline & LM & TAR-0 & TAR-E & MS \\
\hline Threshold & & 0 & -2.111 & \\
\hline Lagged Primary Expenditure & $\begin{array}{l}0.912 * * * \\
(0.025)\end{array}$ & & & \\
\hline Lagged Debt & $\begin{array}{l}0.002 \\
(0.001)\end{array}$ & & & \\
\hline Lagged Output Gap & $\begin{array}{l}0.036 * * \\
(0.012)\end{array}$ & & & \\
\hline Lagged Primary Expenditure - AT or $\mathrm{S}_{1}$ & & $\begin{array}{l}0.931 * * * \\
(0.039)\end{array}$ & $\begin{array}{l}0.944 * * * \\
(0.027)\end{array}$ & $\begin{array}{l}0.961 * * \\
(0.025)\end{array}$ \\
\hline Lagged Primary Expenditure - BT or $\mathrm{S}_{2}$ & & $\begin{array}{l}0.865 * * * \\
(0.036)\end{array}$ & $\begin{array}{l}0.673 * * * \\
(0.060)\end{array}$ & $\begin{array}{l}0.746 * * \\
(0.135)\end{array}$ \\
\hline Lagged Debt - AT or $\mathrm{S}_{1}$ & & $\begin{array}{l}0.002 \\
(0.004)\end{array}$ & $\begin{array}{l}0.003^{*} \\
(0.002)\end{array}$ & $\begin{array}{l}0.007 \\
(0.001)\end{array}$ \\
\hline Lagged Debt - BT or $\mathrm{S}_{2}$ & & $\begin{array}{l}0.001 \\
(0.002)\end{array}$ & $\begin{array}{l}-0.010 * * \\
(0.004)\end{array}$ & $\begin{array}{l}0.008 \\
(0.008)\end{array}$ \\
\hline Lagged Output Gap - AT or $\mathrm{S}_{1}$ & & $\begin{array}{l}-0.009 \\
(0.031)\end{array}$ & $\begin{array}{l}0.012 \\
(0.019)\end{array}$ & $\begin{array}{l}0.017 * * \\
(0.008)\end{array}$ \\
\hline Lagged Output Gap - BT or $\mathrm{S}_{2}$ & & $\begin{array}{l}0.067 * * \\
(0.024)\end{array}$ & $\begin{array}{l}0.080 \\
(0.052)\end{array}$ & $\begin{array}{l}0.073 \\
(0.067)\end{array}$ \\
\hline 1st-regime volatility $\sigma\left(s_{1}\right)$ & & & & $\begin{array}{l}0.172 * * \\
(0.022)\end{array}$ \\
\hline 2nd-regime volatility $\sigma\left(s_{2}\right)$ & & & & $\begin{array}{l}0.874 * * \\
(0.162)\end{array}$ \\
\hline$P_{11}$ & & & & $\begin{array}{l}0.982 * * \\
(0.010)\end{array}$ \\
\hline$P_{22}$ & & & & $\begin{array}{l}0.819 * * \\
(0.030)\end{array}$ \\
\hline$R S S$ & 43.653 & 42.584 & 38.644 & \\
\hline$A I C$ & 929.408 & 931.362 & 907.669 & \\
\hline$S B C$ & 943.397 & 959.339 & 935.646 & \\
\hline log-likelihood $F$ estat & & & & -21.972 \\
\hline Null 1: F-Stat & & 1.480 & 7.648 & \\
\hline
\end{tabular}

Notes: Standard errors in parentheses. One asterisk indicates significance at the $10 \%$ level, while two and three asterisks indicate significance at the 5\% and $1 \%$ level, respectively. RSS, AIC and SBC stand for the residual sum of squares, and the Akaike Information and the Schwarz Bayesian criteria, respectively.

Tables 1 and 2 show the results for the different empirical models with Table 1 showing the results when tax revenue is the dependent variable and Table 2 showing the results when primary expenditure is the dependent variable. Before discussing the results, it is useful to note some of the structure for these tables. The first column presents various parameters, many of which are specific to certain models estimated. ${ }^{12}$ We use the "AT" and "BT" acronym to describe the TR models parameter estimates when the threshold variable is observed to be above the threshold and below the threshold, respectively. The MS models parameters are also listed in the same rows as the TR models to save space even though the parameters have quite different interpretations. In particular, we grouped the AT parameters for the TR models with the state $1, S_{1}$, parameters for the MS models. Similarly, we grouped the BT parameters for the TR models with the state $2, S_{2}$, parameters for the MS models. While there is some reasoning behind grouping these parameters, there are also significant differences in their interpretation which is useful to note. For instance, the AT parameters are the values for the linear portion of the TR models when the output gap is observed to be above the threshold. However, the $S_{I}$ parameter of MS models are the values for the linear portion of the model when the unobserved state variable is in regime 1.

The second column presents the results of the LM given by (1), which was estimated using ordinary least squares (OLS). The remaining columns of the tables present different nonlinear models in which the dependent variable is a nonlinear

\footnotetext{
${ }^{12}$ To save space, results for the constant terms are not reported. Complete tables with all the constant terms can be obtained upon request.
} 
function of the various economic variables. ${ }^{13}$ Columns three and four present the parameter estimates for two versions of the TR model when the lagged output gap is used as the threshold variable. Column three presents the results when the threshold value is set to 0 , while the fourth column presents the estimates for a TR model in which the threshold is endogenously chosen so as to obtain the best fit. These models were also estimated using OLS, although the endogenous threshold model did use an optimal search algorithm as described by Chan (1993) in conjunction with OLS. We distinguish these two columns by using the TR-0 and TR-E notation. The fifth column shows the parameter estimates for the two-state MS formulation. Finally, towards the bottom of the tables are various measures of fit, which are used for comparison purposes between the alternative models.

Focusing on the federal tax revenue results in Table 1, we see the following. The LM model finds the coefficient of the lagged dependent variable is somewhat less than one and is highly significant, which indicates a highly persistent fiscal rule. The lagged debt coefficient is positive and insignificant. As emphasized by Cassou, Shadmani and Vázquez (2017), Collignon (2012), and Bohn (1998), the positive sign on the lagged debt coefficient could be viewed as being consistent with a sustainable fiscal policy in the sense that tax revenue rises in reaction to debt accumulation. However, since it is not significant, there is not enough evidence in support of this interpretation. In addition, the positive and significant coefficient on the lagged output gap indicates that the reactions of tax revenue to economic conditions are countercyclical.

The TR-0 model in column 3 shows that when the economy was both above and below potential output in the previous period (i.e. both above and below the threshold value of zero), the lagged tax revenue coefficients are highly significant and close to one. Furthermore, the coefficients are different in size, which is an indicator of asymmetry. Later we discuss an $F$-test and find that for the TR- 0 model, overall asymmetry is not statistically significant. Next, note that the lagged debt coefficients are positive but insignificant for both the above and below threshold cases. The positive values are consistent with policy makers raising tax revenue in response to high debt levels, but, as noted, this evidence is not statistically significant. The lagged output gap coefficient is negative when the economy was above and positive when the economy was below potential in the previous period; yet, only the below potential coefficient is significant. These show how fiscal policy makers react to business cycle conditions and again show some evidence of asymmetry. In particular, the positive and significant lagged output gap coefficient during below threshold periods implies countercyclical policy. This finding is consistent with the literature which finds that fiscal policy in developed countries tends to be countercyclical. ${ }^{14}$ Moreover, the larger (in absolute value) coefficient during the below threshold case implies that policy makers are more focused on getting the economy back on track during economic downturns. This interpretation is consistent with the asymmetric fiscal policy results found in Balassone et al. (2010) for a sample of fourteen European Union countries and found in Cassou et al. (2017) for the U.S. economy. ${ }^{15}$ Finally, the various fit parameters toward the bottom of the table do not provide strong evidence that the TR-0 model fits better than the simple LM model. Moreover, the null hypothesis that there is no improvement in the fit, as indicated by the row labeled F-Stat, shows an $F$-statistic of 1.480, which is less than the 5\% critical value of 2.410 , and thus cannot be rejected.

The TR-E model in the fourth column of Table 1 shows that the best fitting threshold occurs at a lagged output gap value of -2.111 which is lower than the zero-threshold used in the TR-0 model. ${ }^{16}$ The parameter estimates for this model are largely similar to those for the zero-threshold model and can be more or less interpreted as showing the same asymmetric behavior for government tax revenue. In particular, while the reaction of tax revenue to lagged debt during good times is less significant, the parameter estimates for this variable during bad times provide strong evidence that tax revenue significantly decreases in response to an increase in debt to GDP ratio. This result reinforces our earlier interpretation that concerns toward improving the economy in bad times overwhelm sustainability concerns. Furthermore, both of the coefficients for lagged output gap are positive and the one for below threshold periods is bigger in absolute value. However, because neither is significant, this does not provide strong evidence for the asymmetric reaction. Finally, looking at the various measures of fit at the bottom of the fourth column we see that the

\footnotetext{
${ }^{13}$ It is useful to note that while TR models are linear in the interaction terms denoted in equation (2), they are nonlinear in the economic variables.

${ }^{14}$ In developing countries fiscal policy tends to be procyclical. This was noted by Kandil and Morsyb (2014) who argue that such countries have limited access to international funds, and concerns about policy credibility and unsustainability result in them not having sufficient resources to finance stimulus during recessions.

${ }^{15}$ Balassone et al. (2010) and Cassou et al. (2017) show a strong countercyclical response when economic conditions arepoor.

${ }^{16} \mathrm{~A}$ threshold of 0 implies that below threshold cases occur when the growth rate is below the average growth rate for the economy, while a threshold of -2.111 is more consistent with splitting the sample into recessionary and expansionary cases.
} 
endogenous TR model fits better than the TR-0 model and the LM model. The test that this model fits no better than the LM model, has an $F$-statistic of 7.648, which is larger than the 5\% critical value of 4.119 , and thus is easily rejected. ${ }^{17}$ Here we see the TR-E shows statistically significant evidence of asymmetric behavior in tax revenue.

Finally, the fifth column of Table 1 displays the parameter estimates for the two-state MS model when the dependent variable is tax revenue. Before describing the estimation results, it is useful to study Figure 2 in order to understand how to interpret the two-state conditions. Figure 2 shows the smoothed probability of state 1 for the MS model. ${ }^{18}$ Like Figure 1, Figure 2 also shows the recessionary phases of the business cycle using shaded regions. Focusing on the booming economic period of the 1990s, one can see that the probability of being in state 1 is very high. Similarly, during the boom period of the mid 2000s, Figure 2 shows a high probability of being in state 1 . In addition, the shaded recessionary periods can often be seen it the gaps between the dark regions. Overall, these high probabilities for state 1 during good economic times can be interpreted as indicating that state 1 is generally associated with good economic times and, correspondingly, state 2 is generally associated with poor economic times. Moreover, state 1 is also strongly associated with the Great Moderation period, which is characterized by low volatility. ${ }^{19}$

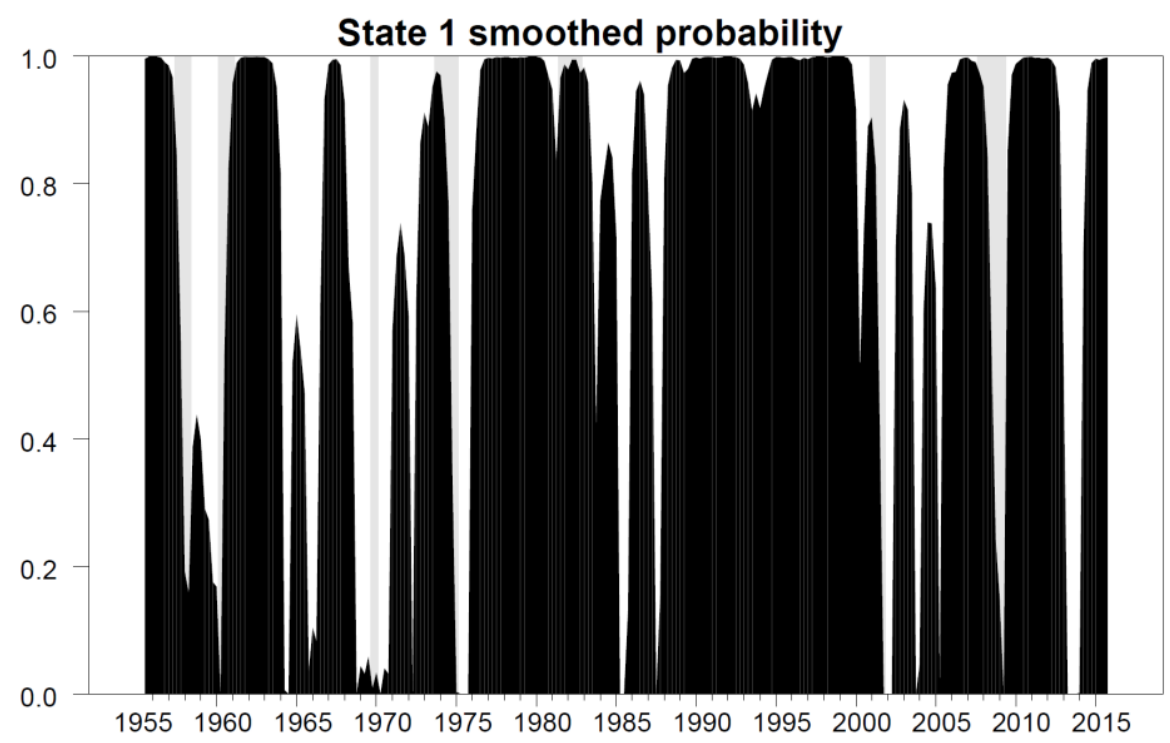

Figure 2. Two-State MS Model (Tax Revenue)

Now focusing on the parameter estimates in column five of Table 1, we see that the lagged tax revenue coefficients are close to one and significant in both states, with a bit larger value for state 1 compared to state 2 . Also, these coefficients have different sizes and are somewhat indicative of asymmetric behavior. The response to lagged debt shows positive and insignificant coefficients for both states while the response to the lagged output gap is positive for both states but only significant for state 1 . The positive lagged output gap sign implies countercyclical behavior, and comparing the size of coefficients implies stronger countercyclical behavior during bad economic times. These differences also are indicative of asymmetric reactions to the lagged output gap, although the insignificant values for state 2 weakens this interpretation. Next note that the volatility of innovations in state $1, \sigma\left(\mathrm{s}_{1}\right)$, is roughly five times lower than the volatility of innovations in state 2, $\sigma\left(\mathrm{s}_{2}\right)$. This is in line with our interpretation of state 1 being mostly associated with the Great Moderation period, which is characterized by low volatility. When comparing the results from TR models with the MS model, one can see that the change in volatility is uncovered by the MS formulation while the TR formulation assumes an identical level of innovation volatility both above and below the threshold level. Finally let us comment a bit on the parameters for the transition probabilities in the MS model. We see that probability of staying in state 1 if one begins

\footnotetext{
${ }^{17}$ The critical value of 4.122 does not come from a conventional $F$ distribution table. We computed this number by using a bootstrap simulation procedure described in Hansen (1997) which showed that the $F$-statistic in TR models do not have $F$ distributions and that proper critical values can be found using a bootstrap procedure.

${ }^{18}$ The smoothed probabilities are computed using the information over the whole sample of size $T$ (i.e., prob $\left[s_{t}=1 \mid I_{T}\right]$ ) as discussed in Hamilton (1994, p. 694).

${ }^{19}$ The precise dating for the Great Moderation is the subject of debate, but many studies, such as Stock and Watson (2002), have suggested this low volatility period starts around 1984. Furthermore, although the debate is still open, the end of this low volatility period likely ended with the financial crisis in late 2007.
} 
in state $1, P_{11}$, is very high at 0.975 , while the probability of staying in state 2 if one begins in state $2, P_{22}$, is smaller at 0.843. These estimates show that there is high persistence for both states, with the persistence during good times being larger.

Overall, we can say that the results for the tax revenue regressions provide strong evidence for policy inertia, with significant coefficients for lagged tax revenue in every model. Furthermore, the differences in these coefficient sizes provide evidence for asymmetric behavior. The response of tax revenue to lagged debt is typically positive, indicating that revenue rises when debt rises. However, the lack of significant coefficients means that this interpretation only has weak evidence. The response to the output gap is mostly positive, indicating that falling output gaps, as one might see in a recession, lead to falling tax revenue, thus countercyclical policy. Furthermore, the coefficients indicate asymmetric behavior, with stronger action taken during weak economic times. Finally, the TR-E model shows significant differences from the LM model providing evidence for overall asymmetric policy behavior.

Next consider the results in Table 2 where the dependent variable is government primary expenditure. The LM finds the lagged dependent variable is close to one and is highly significant, showing evidence of persistence in expenditure policy. The lagged debt coefficient is negative but insignificant. The lagged output gap coefficient is negative and significant implying that the behavior of primary expenditure is countercyclical.

Column three of Table 2, which shows the results for the TR-0 model, also shows that when the economy was both above and below potential output in the previous period, the lagged primary expenditure coefficients are highly significant and close to one. The lagged debt coefficient is negative and insignificant when the economy was above potential and positive and insignificant when the economy was below potential. Furthermore, the lagged output gap coefficients are negative when the economy was both above and below potential in the previous period, but only the below threshold coefficient is significant. The signs of the coefficients for lagged debts are in line with our earlier interpretation that policy makers are more concerned with getting the economy back on track during the bad times, and therefore they increase government expenditure in an effort to revive the economy. However, none of these parameters are significant, so these results do not provide statistically significant support for this interpretation. A similar asymmetric interpretation can be made for the lagged output gap coefficients. In particular, the larger (in absolute value) and significant coefficient during the below threshold case shows that fiscal policy is more focused on mitigating economic downturns than muting booms. The various fit parameters toward the bottom of the table, however, do not show much improvement in the fit of TR-0 model over the basic LM. Moreover, the null hypothesis that there is no improvement in the fit, shows an $F$-statistic of 1.784 , which is less than the 5\% critical value of 2.410 , and thus cannot be rejected.

The fourth column of Table 2, which shows the results for the TR-E model, shows that the best fitting endogenous threshold model is achieved at the lagged output gap value of -2.149 which is lower than the zero-threshold used in the TR-0 model. The parameter estimates for this model are similar to those for the zero-threshold model and can be interpreted as showing the same policy persistence, asymmetric and countercyclical behavior for the government primary expenditure. In particular, we again see significant coefficients on the lagged expenditure terms with values near one indicating a high level of policy persistence. In addition, although the coefficients for lagged debt are not significant and do not provide strong evidence for asymmetric behavior, the coefficients for lagged output gap imply significant countercyclical reactions of primary expenditure to the economy. Moreover, these reactions are asymmetric in that there is a greater level of intervention during economic downturns where we see the coefficient is highly significant and larger, in absolute value than the coefficient during strong economic times. Finally, looking at the various measures of fit at the bottom of the fourth column we see that the endogenous threshold TR model fits somewhat better than the zero threshold TR model. However, the test that this model fits no better than the LM model, as indicated by the row labeled F-Stat, has an F-statistic of 2.587, which is not larger than the 5\% critical value of 4.119 , and thus cannot be rejected. 
Table 2. Federal Government Primary Expenditure (1955:1 - 2015:4)

\begin{tabular}{|c|c|c|c|c|}
\hline & LM & TAR-0 & TAR-E & MS \\
\hline Threshold & & 0 & -2.149 & \\
\hline Lagged Primary Expenditure & $\begin{array}{l}0.949 * * * \\
(0.016)\end{array}$ & & & \\
\hline Lagged Debt & $\begin{array}{l}-0.0004 \\
(0.001)\end{array}$ & & & \\
\hline Lagged Output Gap & $\begin{array}{l}-0.061 * * * \\
(0.011)\end{array}$ & & & \\
\hline Lagged Primary Expenditure - AT or $\mathrm{S}_{1}$ & & $\begin{array}{l}0.915 * * * \\
(0.033)\end{array}$ & $\begin{array}{l}0.952 * * * \\
(0.017)\end{array}$ & $\begin{array}{l}0.965 * * \\
(0.014)\end{array}$ \\
\hline Lagged Primary Expenditure - BT or $\mathrm{S}_{2}$ & & $\begin{array}{l}0.947 * * * \\
(0.021)\end{array}$ & $\begin{array}{l}0.913 * * * \\
(0.038)\end{array}$ & $\begin{array}{l}0.929 * * \\
(0.060)\end{array}$ \\
\hline Lagged Debt - AT or $\mathrm{S}_{s_{2}}$ & & $\begin{array}{l}-0.004 \\
(0.003)\end{array}$ & $\begin{array}{l}-0.001 \\
(0.002)\end{array}$ & $\begin{array}{l}-0.003 * * \\
(0.001)\end{array}$ \\
\hline Lagged Debt - BT or $\mathrm{S}_{2}$ & & $\begin{array}{l}0.0008 \\
(0.002)\end{array}$ & $\begin{array}{l}0.003 \\
(0.003)\end{array}$ & $\begin{array}{l}0.005 \\
(0.010)\end{array}$ \\
\hline Lagged Output Gap - AT or $\mathrm{S}_{1}$ & & $\begin{array}{l}-0.036 \\
(0.029)\end{array}$ & $\begin{array}{l}-0.055^{* *} \\
(0.017)\end{array}$ & $\begin{array}{l}-0.053 * * \\
(0.013)\end{array}$ \\
\hline Lagged Output Gap - BT or $\mathrm{S}_{2}$ & & $\begin{array}{l}-0.085 * * * \\
(0.021)\end{array}$ & $\begin{array}{l}-0.198 * * * \\
(0.048)\end{array}$ & $\begin{array}{l}-0.002 \\
(0.003)\end{array}$ \\
\hline 1st-regime volatility $\sigma\left(s_{1}\right)$ & & & & $\begin{array}{l}0.107 * * \\
(0.016)\end{array}$ \\
\hline 2nd-regime volatility $\sigma\left(s_{2}\right)$ & & & & $\begin{array}{l}0.803 * * \\
(0.196)\end{array}$ \\
\hline$P_{11}$ & & & & $\begin{array}{l}0.971 * * \\
(0.008)\end{array}$ \\
\hline$P_{22}$ & & & & $\begin{array}{l}0.867 * * \\
(0.022)\end{array}$ \\
\hline$R S S$ & 32.947 & 32.094 & 31.563 & \\
\hline$A I C$ & 860.758 & 862.353 & 858.287 & \\
\hline$S B C$ & 874.747 & 890.331 & 886.264 & \\
\hline $\begin{array}{l}\text { log-likelihood F-stat } \\
\text { Null 1:F-Stat }\end{array}$ & & 1.569 & 2.587 & -44.735 \\
\hline
\end{tabular}

Notes: Standard errors in parentheses. One asterisk indicates significance at the $10 \%$ level, while two and three asterisks indicate significance at the 5\% and $1 \%$ level, respectively. RSS, AIC and SBC stand for the residual sum of squares, and the Akaike Information and the Schwarz Bayesian criteria, respectively.

Before describing the estimation results for the government spending version of the MS model, let us study Figure 3 in order to understand how to interpret the two-state conditions. Unlike the model for tax revenue where state 1 was generally lined up with the boom periods and state 2 was generally lined up with recessions, Figure 3 does not clearly separate good times from bad times. In particular, Figure 3 shows that the probability of being in state 2 is not only high in recession periods, but is also high in some of the boom periods. Therefore, the interpretations for these coefficients are not quite the same as described for the TR models. However, Figure 3 does show that state 2 is largely associated with the periods prior to the 1980s, the late 1990s, late 2000s, and early 2010s which are generally lined up with the periods when democratic parties dominated the political scene, while state 1 is largely lined up with the periods when conservative parties held greater power. 


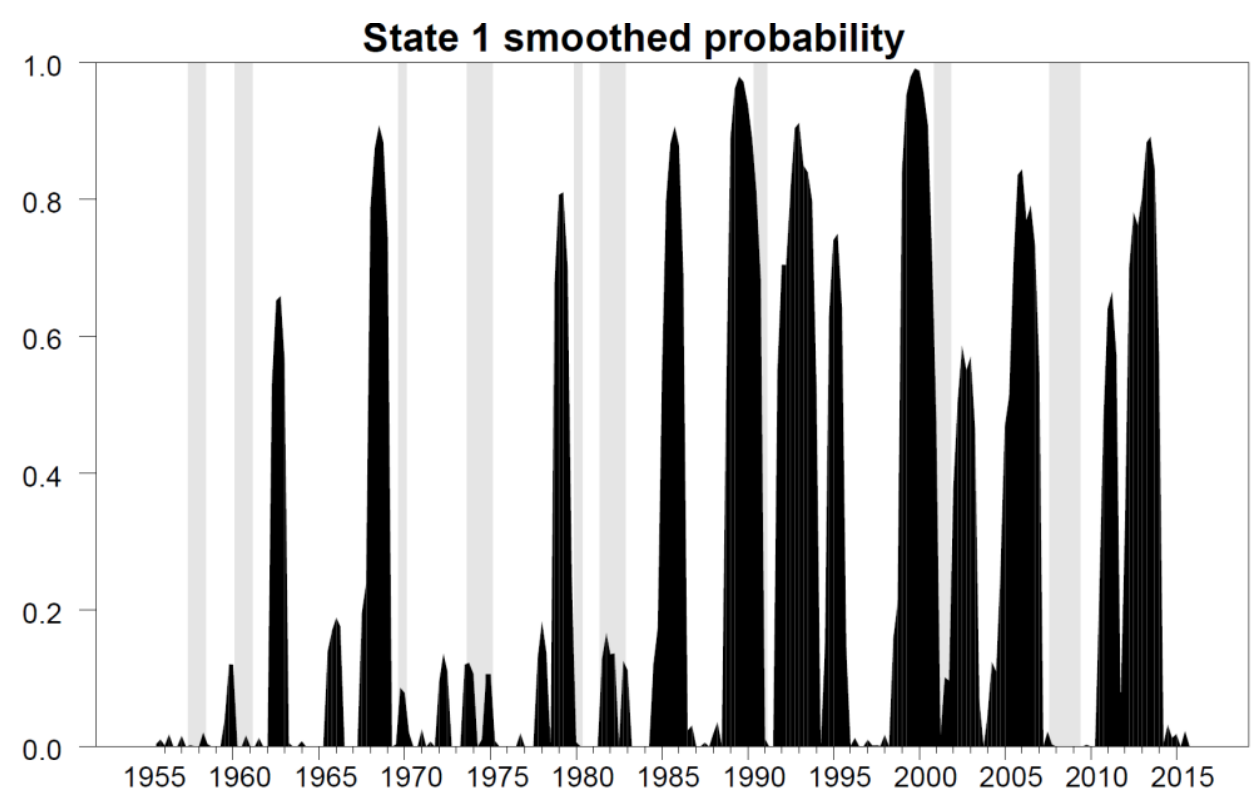

Figure 3. Two-State MS Model (Primary Expenditure)

Focusing on the parameter estimates in column five of Table 2, we see that the lagged dependent variable coefficients are near one and significant in both states. The response to lagged debt is negative and significant for state 1 and positive and insignificant for state 2 . The response to the lagged output gap is negative in both states and it is highly significant in state 1 implying counter cyclical policy, but insignificant in state 2 . Moreover, the volatility of innovations in state $1, \sigma\left(\mathrm{s}_{1}\right)$, is roughly four times lower than the volatility of innovations in state $2, \sigma\left(\mathrm{s}_{2}\right)$. Since state 1 is roughly associated with the republican periods and state 2 is roughly associated with the democratic periods, one interpretation for the parameter estimates is that government expenditure tends to decrease in response to an increase in debt during republican periods, while it tends to increase during democratic periods. Furthermore, the negative and significant response to lagged output gap for state 1 with the larger value (in absolute value) implies a higher level of countercyclical policy in this state. Finally, it is useful to recall that our main purpose is to investigate the asymmetry in the reaction of each budget component to debt levels and economic conditions over the cycle. Therefore, the results for the MS expenditure regression are not as useful as for tax revenue regression since it cannot clearly separate economic good times from bad times. Hence, one can conclude that when the dependent variable is government expenditure, the TR models provide a better interpretation for our goal.

To check the robustness of these results, we also estimated our equations as a system using the SUR estimation method. This type of estimation is motivated by Figure 1 where the movements in tax revenue and government primary expenditure over time seem to be related. The results from the SUR estimation are in line with those presented above and are not presented here to save space. ${ }^{20}$

Let us conclude this section with a brief summary of the key findings. In general, we found that there was a sequence of improvements in the fit and performance of the models presented. While the LM found that both types of policy are highly persistent, are consistent with debt sustainability and exhibit countercyclical behavior, it did not perform as well as the TR models and the MS models which allowed asymmetric policy behavior. For the tax revenue series, the TR-E model showed significance improvements in fit, while for the government spending series the fit was not significantly improved. Furthermore, one should note that the interpretation of two regimes for government spending MS model are not as useful for investigating asymmetric policy during good and bad economic times as the MS model was for the tax revenue case. In particular, in the MS model for tax revenue, state 1 is generally associated with economic good times and state 2 is associated with bad time. This interpretation is in line with the purpose of this paper as it allows us to study the reactions of tax revenue to different variables depending on the strength of economy. However, the MS model for government expenditure does not necessarily assign the observations into each state in a way which aligns with our purpose.

\footnotetext{
${ }^{20}$ SUR results are presented in Tables A1 and A2 of the Appendix.
} 


\section{Conclusion}

This paper investigates US federal government tax and spending policy reaction functions using quarterly data over the period of 1955:1 to 2015:4. We investigate several issues including, policy persistence, the response to debt levels, the response to economic conditions and most importantly whether these responses are asymmetric between good and bad economic times. We find several important results for both budget components. First, both sides of the budget show that there is a high degree of policy persistence, that policy responds to higher debt and to business cycle conditions. However, the statistical significance of these responses is only strong for policy persistence, while the response to economic conditions is statistically significant most of the time and the response to debt levels is statistically significant in only a few models. In addition, both tax revenue and government spending exhibit asymmetric behavior, but only in the tax revenue endogenous threshold model do we find this to be statistically significant. Because the linear model is not nested in the Markov Switching model, directly testing this hypothesis is not feasible. However, the coefficient estimates in the tax revenue Markov Switching model does exhibit the same level of asymmetry as those in the endogenous threshold model. Taken as a whole, these results show that policy makers undertake asymmetric countercyclical policy, with stronger action taken when the poor economic conditions prevail. Moreover, the response to lagged debt also has a countercyclical policy interpretation. In particular, one can interpret the finding that during good economic times policy makers increase taxes and cut spending in response to rising debt to a greater extent than in poor economic times as also showing countercyclical behavior.

\section{Acknowledgements}

We are grateful for helpful comments from Bill Blankenau, Lance Bachmeier, Jesus Vazquez, William Vasquez, and seminar participants at the 43rd Annual Conference of Eastern Economic Association (NYC, USA) and the 91st Annual Conference of the Western Economic Association International (Portland, USA) on earlier drafts of the paper.

\section{References}

Afonso, A., Agnello, L., \& Furceri, D. (2010). Fiscal policy responsiveness, persistence, and discretion. Public Choice 145, 503-530. https://doi.org/10.1007/s11127-009-9577-x

Auerbach, A. J., \& Gorodnichenko, Y. (2012). Measuring the output responses to fiscal policy. American Economic Journal: Economic Policy, 4(2), 1-27. https://doi.org/10.1257/pol.4.2.1

Balassone, F., Francese, M., \& Zotteri, S. (2010). Cyclical asymmetry in fiscal variables in the EU. Empirica, 37, 381-402. https://doi.org/10.1007/s10663-009-9114-7

Bohn, H. (1998). The behavior of US public debt and deficits. The Quarterly Journal of Economics, 113, 949-963. https://doi.org/10.1162/003355398555793

Bohn, H. (2007). Are stationarity and cointegration restrictions really necessary for the intertemporal budget constraint? Journal of Monetary Economics, 54, 1837-1847. https://doi.org/10.1016/j.jmoneco.2006.12.012

Cassou, S. P., Scott, C. P., \& Vázquez, J. (2012). Optimal monetary policy with asymmetric preferences for output. Economic Letters, 117, 654-656. https://doi.org/10.1016/j.econlet.2012.08.009

Cassou, S. P., Shadmani, H., \& Vázquez, J. (2013). Did asymmetric monetary preferences for the output gap disappear during recent economic times? Applied Economic Letters, 21, 113-117. https://doi.org/10.1080/13504851.2013.842631

Cassou, S. P., Shadmani, H., \& Vázquez, J. (2017). Fiscal policy asymmetries and the sustainability of US government debt revisited. Empirical Economics, 53, 1193-1215. https://doi.org/10.1007/s00181-016-1159-4

Chan, K. S. (1993). Consistency and limiting distribution of the least squares estimator of a threshold autoregressive model. The Annals of Statistics, 21, 520-533. https://doi.org/10.1214/aos/1176349040

Collignon, S. (2012). Fiscal policy rules and the sustainability of public debt in Europe. International Economic Review, 53, 539-567. https://doi.org/10.1111/j.1468-2354.2012.00691.x

Golinelli, R., \& Momigliano, S. (2008). The cyclical response of fiscal policies in the Euro area. Why results of empirical research differ so strongly? Banca d'Italia Temi di Discussione 654.

Hakkio, C. S., \& Rush, M. (1991). Is the budget deficit too large? Economic Inquiry, 24, 429-445. https://doi.org/10.1111/j.1465-7295.1991.tb00837.x

Hamilton, J. D. (1994). Time Series Analysis. New Jersey: Princeton University Press.

Hansen, B. (1997). Inference in TAR models. Studies in Nonlinear Dynamics and Econometrics, 2, 1-14. https://doi.org/10.2202/1558-3708.1024

Kandil, M., \& Morsyb, H. (2014). Fiscal Stimulus and Credibility in Emerging Countries. Eastern Economic Journal, 
40, 420-439. https://doi.org/10.1057/eej.2013.25

Kremers, J. M. (1989). US Federal indebtedness and the conduct of fiscal policy. Journal of Monetary Economics, 23, 219-238. https://doi.org/10.1016/0304-3932(89)90049-4

Quintos, C. E. (1995) Sustainability of the deficit process with structural shifts. Journal of Business and Economic Statistics, 13, 409-417.

Ramey, V. A., \& Zubairy, S. (2017). Government spending multipliers in good times and in bad: evidence from US historical data. Journal of Political Economy (forthcoming). https://doi.org/10.1086/696277

Ruge, M. F. J. (2003). Does the Barro-Gordon model explain the behavior of US inflation? A reexamination of the empirical evidence, Journal of Monetary Economics, $50, \quad 1375-90$. https://doi.org/10.1016/S0304-3932(03)00083-7

Ruge, M. F. J. (2004). The inflation bias when the central bank targets the natural rate of unemployment, European Economic Review, 48, 91-107. https://doi.org/10.1016/S0014-2921(02)00237-4

Sorensen, B., \& Yosha, O. (2001). Is state fiscal policy asymmetric over the business cycle? Economic Review, 86(3), 43-64.

Stock, J., \& Watson, M. W. (2002). Has the business cycle changed and why? in Gertler, M., and K. S. Rogoff (eds.) NBER Macroeconomics Annual, Cambridge, MA: MIT Press, 159-218. https://doi.org/10.1086/ma.17.3585284

Surico, P. (2007). The Fed's monetary policy rule and U.S. inflation: The case of asymmetric preferences. Journal of Economic Dynamics and Control, 31, 3305-324. https://doi.org/10.1016/j.jedc.2005.11.001

Trehan, B., \& Walsh, C. (1988). Common trends, the government budget constraint, and revenue smoothing. Journal of Economic Dynamics and Control, 12, 425-444. https://doi.org/10.1016/0165-1889(88)90048-6

\section{Appendix}

Table A1. Federal Government Tax Revenue (1955:1 - 2015:4) - SUR

\begin{tabular}{|c|c|c|c|}
\hline & LM & TAR-0 & TAR-E \\
\hline Threshold & & 0 & -2.110 \\
\hline Lagged Primary Expenditure & $\begin{array}{l}0.912 * * * \\
(0.025)\end{array}$ & & \\
\hline Lagged Debt & $\begin{array}{l}0.002 \\
(0.001)\end{array}$ & & \\
\hline Lagged Output Gap & $\begin{array}{l}0.036^{* *} \\
(0.012)\end{array}$ & & \\
\hline Lagged Primary Expenditure - AT or $\mathrm{S}_{1}$ & & $0.929 * * *$ & $0.945^{* * *}$ \\
\hline Lagged Primary Expenditure - BT or $\mathrm{S}_{2}{ }_{s_{1}}^{s_{2}}$ & & $\begin{array}{l}(0.038) \\
0.873 * * * \\
(0.035)\end{array}$ & $\begin{array}{l}(0.027) \\
0.686 * * * \\
(0.060)\end{array}$ \\
\hline Lagged Debt - AT or $\mathrm{S}_{1}^{S_{1}}$ & & $\begin{array}{l}0.002 \\
(0.004)\end{array}$ & $\begin{array}{l}0.003 * \\
(0.002)\end{array}$ \\
\hline Lagged Debt - BT or $\mathrm{S}_{2}$ & & $\begin{array}{l}0.001 \\
(0.002)\end{array}$ & $\begin{array}{l}-0.010 * * \\
(0.004)\end{array}$ \\
\hline Lagged Output Gap - AT or $\mathrm{S}_{1}$ & & $\begin{array}{l}-0.009 \\
(0.031)\end{array}$ & $\begin{array}{l}0.013 \\
(0.018)\end{array}$ \\
\hline Lagged Output Gap - BT or $S_{2}$ & & $\begin{array}{l}0.065^{* *} \\
(0.024)\end{array}$ & $\begin{array}{l}0.075 \\
(0.051)\end{array}$ \\
\hline$R S S$ & 43.652 & 42.595 & 38.652 \\
\hline$A I C$ & 937.408 & 947.425 & 923.723 \\
\hline$S B C \quad$ Festat & 965.385 & 1003.379 & 979.678 \\
\hline Null 1: F-Stat & & 1.465 & 7.633 \\
\hline
\end{tabular}

Notes: Standard errors in parentheses. One asterisk indicates significance at the $10 \%$ level, while two and three asterisks indicate significance at the 5\% and $1 \%$ level, respectively. RSS, AIC and SBC stand for the residual sum of squares, and the Akaike Information and the Schwarz Bayesian criteria, respectively. 
Table A2. Federal Government Primary Expenditure (1955:1 - 2015:4)- SUR

\begin{tabular}{|c|c|c|c|}
\hline & LM & TAR-0 & TAR-E \\
\hline Threshold & & 0 & -2.149 \\
\hline Lagged Primary Expenditure & $\begin{array}{l}0.954 * * * \\
(0.015)\end{array}$ & & \\
\hline Lagged Debt & $\begin{array}{l}-0.0005 \\
(0.001)\end{array}$ & & \\
\hline Lagged Output Gap & $\begin{array}{l}-0.060 * * * \\
(0.011)\end{array}$ & & \\
\hline Lagged Primary Expenditure - AT or $S_{1}$ & & $0.920 * * *$ & $0.955 * * *$ \\
\hline Lagged Primary Expenditure - BT or $\mathrm{S}_{2}{ }_{s_{1}}^{s_{2}}$ & & $\begin{array}{l}(0.032) \\
0.954 * * * \\
(0.021)\end{array}$ & $\begin{array}{l}(0.016) \\
0.922^{* * * *} \\
(0.037)\end{array}$ \\
\hline Lagged Debt - AT or $\mathrm{S}_{1}$ & & $\begin{array}{l}-0.004 \\
(0.003)\end{array}$ & $\begin{array}{l}-0.001 \\
(0.002)\end{array}$ \\
\hline Lagged Debt - BT or $\mathrm{S}_{2}$ & & $\begin{array}{l}0.0004 \\
(0.002)\end{array}$ & $\begin{array}{l}0.003 \\
(0.003)\end{array}$ \\
\hline Lagged Output Gap - AT or $\mathrm{S}_{1}$ & & $\begin{array}{l}-0.034 \\
(0.029)\end{array}$ & $\begin{array}{l}-0.053 * * \\
(0.017)\end{array}$ \\
\hline Lagged Output Gap - BT or $\mathrm{S}_{2}$ & & $\begin{array}{l}-0.083 * * * \\
(0.021)\end{array}$ & $\begin{array}{l}-0.188 * * * \\
(0.047)\end{array}$ \\
\hline$R S S$ & 32.959 & 32.109 & 31.580 \\
\hline$A I C$ & 868.844 & 878.470 & 874.418 \\
\hline$S B C$ & 896.822 & 934.425 & 930.372 \\
\hline Null 1: F-Stat & & 1.540 & 2.554 \\
\hline
\end{tabular}

Notes: Standard errors in parentheses. One asterisk indicates significance at the $10 \%$ level, while two and three asterisks indicate significance at the $5 \%$ and $1 \%$ level, respectively. RSS, AIC and SBC stand for the residual sum of squares, and the Akaike Information and the Schwarz Bayesian criteria, respectively.

\section{Copyrights}

Copyright for this article is retained by the author(s), with first publication rights granted to the journal.

This is an open-access article distributed under the terms and conditions of the Creative Commons Attribution license which permits unrestricted use, distribution, and reproduction in any medium, provided the original work is properly cited. 